Andreas Maurer

\title{
Lex Maritima
}

\section{Grundzüge eines transnationalen Seehandelsrechts}

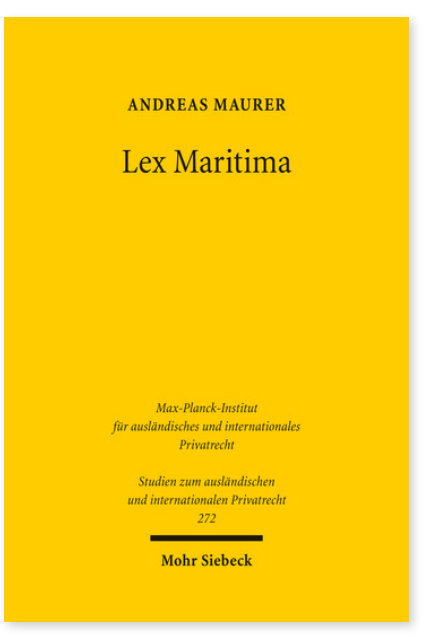

2012. XVII, 260 Seiten. StudIPR 272

ISBN 978-3-16-152022-8

DOI 10.1628/978-3-16-152022-8

eBook PDF 74,00€

ISBN 978-3-16-151781-5

fadengeheftete Broschur 74,00€
In der Rechtswissenschaft werden unter den Stichworten »Neue Lex Mercatoria« und »Transnationales Recht « seit Jahrzehnten Konzepte eines globalisierten Rechts jenseits des Nationalstaats diskutiert. Weitgehend unbeachtet von derartigen Debatten hat die Seehandelsbranche aufgrund ihrer eigenen Internationalität die Globalisierung bereits seit langem tatsächlich vollzogen. Der grenzüberschreitende Seehandel hat dabei Institutionen im Bereich von Rechtsetzung Rechtsprechung und Rechtsdurchsetzung entwickelt, die aufgrund privater Setzung ein transnationales Seehandelsrecht begründen. Regeln entstehen dabei in Verfahren, die unter breiter Beteiligung von allen Interessenträgern des Seehandels zustande kommen. Diese dienen als Beispiel für die Legitimation eines transnationalen Rechts, das mit staatlichem Recht interagiert und so einen hybriden Rechtskörper - eine Lex Maritima - bildet.

Andreas Maurer Geboren 1976; Studium der Rechtswissenschaften und anschließendes Referendariat in Frankfurt am Main Wissenschaftlicher Mitarbeiter zunächst an der Johann-Wolfgang-Goethe Universität Frankfurt am Main, danach seit 2007 an der Universität Bremen; 2006/2007 LL.M. Studium an der Osgoode Hall Law School, Toronto; 2011 Promotion.

Jetzt bestellen:

https://mohrsiebeck.com/buch/lex-maritima-9783161520228?no_cache=1

order@mohrsiebeck.com

Telefon: +49 (0)7071-923-17

Telefax: $+49(0) 7071-51104$ 